\title{
NATURE OF SCIENCE INTERDISCIPLINARY TEACHING BASED ON SYMMETRY AND THE SEARCH OF INVARIANTS
}

\author{
Simone Brasili ${ }^{1}, \&$ Riccardo Piergallini ${ }^{2}$

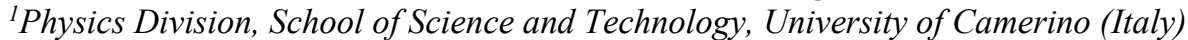 \\ ${ }^{2}$ Mathematics Division, School of Science and Technology, University of Camerino (Italy)
}

\begin{abstract}
The project is situated in the field of teaching physics, generally speaking science education, and aims at studying the interplay between physics and mathematics. Although mathematics has always been closely related to physics, the two disciplines are different in objects, aims, methods and tools. Nevertheless, mathematics provides physics with the language it needs. The result is that students are more concerned with the mathematical machinery rather than with a proper understanding of the physical situation. Remarkable studies (Boniolo, G., Budinich, P. and Trobok, M. (2005); Fuson, K. C., Kalchman, M., \& Bransford, J. D. (2005)) have been devoted to the problem of teaching together mathematical and science contents. In addition, the language of mathematics makes sense of a wide range of natural phenomena. Despite the fact that mathematical proficiency is highly relevant in and to the research fields, mathematics education is failing to support interdisciplinary and educational connections to physics. The main focus of our study is on how to grasp the challenges of an interdisciplinary approach based on symmetry and invariance. Symmetry and searching of invariants can be employed in interdisciplinary perspective because of its crosscutting character and its historico-epistemological value. In order to test the positive effect of introducing the modern concept of symmetry viewed as sameness within change, we designed and implemented a teaching learning sequence (TLS) according to the didactical framework created by the Claus Michelsen (Michelsen C. 2015). On our side we also introduced interdisciplinary modules in history of physics and education, typically of Nature of Science (NoS) modelling. The materials have been implemented to 96 pupils of primary school in Italy. The data analysis shows that the pupils were in the regime of competence for grasping the changed view of symmetry linked to the search for invariance. It also provides ways for further research.
\end{abstract}

Keywords: Teaching science, NoS, symmetry, invariants in science education.

\section{Introduction}

\subsection{Background}

Remarkable studies (Pisano; Matthews, Boniolo, G., Budinich, P. and Trobok, M. (2005); Fuson, K. C., Kalchman, M., \& Bransford, J. D. (2005)) have been devoted to the problem of teaching together mathematical and science contents. In addition, the language of mathematics makes sense of a wide range of natural phenomena.

Despite the fact that mathematical proficiency is highly relevant in and to the research fields, mathematics education is failing to support interdisciplinary and educational connections to physics. In fact, sometimes from students' prospective, mathematics, physics and biology typically appear as separate subjects with few interconnections (cf. Redish, E. F. and Kuo, 2015).

This compartmentalization generates many theoretical misunderstandings in the process of learning certain important concepts (cf. Meltzer, D. E. 2002; Buick, J. M., 2007). For instance, students showing adequate computational skills still lack the ability to apply these skills in a meaningful way. It means that students focus their attention more on basic comprehension and memorization of concepts and formulas than on critical thinking. In this sense, a key aspect of educational innovation is to promote creative and flexible frameworks for integrating productive ideas across disciplines.

\subsection{Focus of the study and literature review}

Our project aims at contributing to the research in the field of Nature of Science Teaching regarding the interplay between physics and mathematics (cf. Pisano; Doran Y. J. (2017); Wigner, E. P. (1960)) within an interdisciplinary approach based on symmetry and invariance. Symmetry and searching 
of invariants can be employed in interdisciplinary perspective because of its crosscutting character and its historico-epistemological value (cf. Dirac, P. A. M. (1939); Feynman, R. (1964-1965); Galileo, G., 11 Saggiatore (1623)). The possibility of widening the fields of application in which to choose the rules to be considered from time to time offers the starting point for reflections on the relationships of equality and more generally of equivalence, on the relativity of the concept of equality, of form as a physical system that is preserved (cf. Rosen, J. and P. Copie' (1982); Weyl, H. (1928); Wigner, E. P. (1967)).

The processes of change or modelling of a rule are themselves subject to a principle of legality that guarantees compatibility and consistency with those already in existence: in physics, this set of binding conditions is represented by the principles of symmetry. The symmetry perceived with the meaning of the invariance of a form undergoing a change becomes a powerful tool of inter-disciplinary knowledge included applied sciences both into history and in society (e.g., micro devices and their technology); (Pisano R (2019); Pisano R (2011)).

The essential idea is to extend symmetry starting from line symmetry and aesthetic qualities with the search for regularity to more general and interdisciplinary aspect of dynamic principles of transformation (cf. Leikin R., Bernan A., Zaslavsky O. 2000). In fact, the figures that have characteristics in common to our eye from different points of view somehow refer to the concept of invariant to the sameness within change (cf. Thyssen P. and Ceulemans A. (2017); Weyl, H. (1952)).

The search for invariants is inherent in the description of reality, introducing dynamic principles of transformation that give meaning to the modern concept of symmetry in science. In other words, a system is said to possess a symmetry if one can make a change (a transformation) in the system so that, after the change, the thing appears exactly the same (is invariant) as before (cf. Lederman L. M. and Hill C. T. (2000)).

\subsection{Theoretical framework}

For modelling activities, centred around symmetry, we are inspired by Michelsen's model (Michelsen C. 2015). It consists of an educational framework for coordination and mutual interaction between mathematics and science. It is operative by two phases: horizontal connection and vertical structuring. In the horizontal phase, thematic integration is established to connect concept and process skills of mathematics and science.

The horizontal linking is characterized by process of modelling activities in an interdisciplinary context. In the vertical phase, conceptual anchoring of the concepts and process skills from the horizontal phase is used to create languages and symbol systems that allow the pupils to move about logically and analytically within mathematics and science.

According to this model, the teaching learning progression (TLS) is formed both by an incremental vertical way represented by the development of the concept of symmetry and by a transversal way represented by the ability to use the sameness within change to interpret different material and aspects of these contexts. The vertical and horizontal progression occurs from iterative improvements in which pupils develop the habit of using different articulations of ideas to understand the behaviour of and changes in materials.

Once the concepts and skills in the search of invariants are conceptually anchored in the respective subjects, they can evolve in a new interdisciplinary context, as part of a horizontal linkage. In this way we expect to identify pupils' conceptions and the persistence of these conceptions and to focus the attention on difficulties that children might have in mathematizing physical situations.

\section{Experiment design}

A sample of 96 pupils meaning that all fifth grade classes (10 years) of the primary school in Italy participated in the study.

Table 1.

\begin{tabular}{|c|c|c|c|c|c|}
\hline Classes & $\mathrm{N}^{\circ}$ Pupils & Gender & Pre-Course Test & Course & Post-Course Test \\
\hline V A & 16 & $6 \mathrm{~F}-10 \mathrm{M}$ & No & Yes & Yes \\
\hline V C & 19 & $7 \mathrm{~F}-12 \mathrm{M}$ & No & Yes & Yes \\
\hline V D & 20 & $8 \mathrm{~F}-12 \mathrm{M}$ & No & Yes & Yes \\
\hline V F & 20 & $11 \mathrm{~F}-9 \mathrm{M}$ & Yes & Yes & Yes \\
\hline V G & 21 & $10 \mathrm{~F}-11 \mathrm{M}$ & Yes & Yes & Yes \\
\hline
\end{tabular}


The VF and VG classes, in total 41 pupils, were making up the check group that had to answer the same questionnaire at the beginning and at the end of learning and teaching sequence. The inquiry also concerned all the mathematics teachers, who were in charge of answering pre-course and post-course questionnaires and keeping the logbook of the whole experiment.

\subsection{Activities and materials}

The structure of 5 activities is divided into three stages of 2 hours in sequence. In total the duration is 6 hours where the researcher proposes various activities and the teachers participate in the lessons as observers. The main activity is centered on the task game consisting of closing cardboard boxes, which pupils have to create from the distributed models, and filling out the questionnaire of the task game. This approach implies emphasis on laboratory activities.

Table 2. Series of Activity in TLS.

\begin{tabular}{|c|c|c|c|}
\hline Activity & Type & Title & Duration \\
\hline A1 & Brainstorming - Writing - Drawing & $\begin{array}{c}\text { "If I say the word "symmetry", } \\
\text { what are you thinking about?" }\end{array}$ & $2 \mathrm{~h}$ \\
\hline A2 & Solving Problems & "Boxes and lids" & $1 \mathrm{~h}$ \\
\hline A3 & Listening - Watching & "Lesson" & $1 \mathrm{~h}$ \\
\hline A4 & Task Game in group & "Strange boxes and lids" & $2 \mathrm{~h}$ \\
\hline A5 & Homework task & "Hunting for symmetries". & $/$ \\
\hline
\end{tabular}

The questionnaire is made up of four questions of increasing difficulty, linked with the activities carried on during the teaching learning course in order to help the students to propose more accurate and precise answers.

Table 3. Questionnaire.

\begin{tabular}{|c|c|c|}
\hline Question & Type & Aim \\
\hline Q1 & $\begin{array}{c}\text { Dichotomous Choice } \\
\text { Open Justification }\end{array}$ & $\begin{array}{r}\text { To verify the way the concept of symmetry is perceived in the } \\
\text { adopted didactical frame. }\end{array}$ \\
\hline Q2 & 8 Items Text & $\begin{array}{c}\text { To evaluate and measure the level of knowledge and ability of } \\
\text { the tasks and/or specific scopes of the learning unit. }\end{array}$ \\
\hline Q3 & Narrative Text & $\begin{array}{c}\text { D1: Emotional and affective dimension. } \\
\text { D2: Cognitive dimension of learning. } \\
\text { D3: Possible presence of a cognitive conflict }\end{array}$ \\
\hline Q4 & $\begin{array}{c}\text { A Task Open } \\
\text { Justification }\end{array}$ & $\begin{array}{c}\text { To verify to what extent the students are controlling } \\
\text { the skills in a (task) exercise of higher cognitive difficulty. }\end{array}$ \\
\hline
\end{tabular}

The logical order of the questions is also aimed at stimulating the students in thinking about the whole personal formative process. By asking them to justify their answers, one follows what appears to be the purpose reached and the skills to be acquired, such as they are indicated in the National Guidelines for the Curriculum of the first cycle of education. The time at disposal for answering is of about 45 minutes and it cannot exceed one hour.

\section{Methods}

\subsection{Research questions}

Several notable studies point out that the concepts and the principles of the application of the modern concept of symmetry can be taught and understood at the high school and early college level (Bertozzi E., Levrini O., Rodriguez M (2014)). Our experimental project tries to answer the following General Research Question (GRQ):

How can we use symmetry and the search of invariants as bridging concepts in science education for fifth grade pupils? 
These aims lead to the following Specific Research Questions: development?

SRQ1 What is the effect of this change of paradigm on the students' understanding and skill

SRQ2 What is the effect of this change of paradigm on the didactical framework of linking teaching in Mathematics and Physics?

\subsection{Findings}

In order to answer SRQ1, the analysis of the data shows that the great majority (about 70\%) of the students in the sample has chosen the modern concept of symmetry. As for the students of the check group, they too have preferred the modern concept of symmetry (about $80 \%$ ) in the final questionnaire while having chosen the line symmetry in the initial test (about $83 \%$ ).

The experiment seems therefore to have a very positive effect in changing the view of symmetry linked to the search for invariance in the geometric transformations. However, these results are of little relevance if one doesn't ask the question how students have interpreted, experienced and assimilated the new concept during the course of the teaching-learning unit. In order to make a qualitative comparison, we give here some relevant examples of answers proposed by the pupils of the VF-VG classes at the beginning and at the end of the cycle of lessons.

Pupil VG17, at the beginning, answers the question $\mathrm{Q} 1{ }^{1}$ in the following way: "I have chosen the (a) option because it is the most simple and right way to make the Little Prince understand what symmetry is." In the final questionnaire he offers the following reason of his choice, which at this stage is b: "I have chosen the (b) option because if one observes his surroundings, one can see that although there are plenty of symmetries, if you turn them it sometimes happens that it is as you wouldn't have."

Pupil VG19 answers as follows at the beginning: "I choose (a) because it is clearer than (b)." She answers at the end "I choose (b) because if for instance I take a square and I turn it in different ways, the figure remains always the same".

Pupil VF16 at the beginning: "I made this choice (a) because it offers a simple and right explanation that makes the Little Prince understand what symmetry is." At the final test: "I have chosen (b) because it is true that there exist so many symmetries, as the rotation, that transform a figure, and this transformed figure is really coincident with the original one."

In order to answer SRQ2, we have picked out the most frequent keywords, the most recurrent and significant arguments that appear in the justifications in order to classify them in thematic groups according to the aims of the TLS. The expressions "many symmetries", "movements", "transformations", "palindrome", "coincidence with the original" occurring in the answers to the final questionnaire are almost absent in the answers to the initial one.

This result means that the TLS helped the students to take an active part in acquiring a new lexicon and also that they became able to cognitively elaborate, at least to some extent, the new concepts, and to review the concepts they had already acquired. The ability of some pupils to shape the experience can sometimes result in metacognitive skills developing original and unexpected explanations. Very interesting is the answer of VF4, which shows the ability to extend the meaning of symmetry because VF4 interprets the palindromic characteristic of the short film entitled "Palindromic Film" by association of thought with the argument a certain symmetry of time.

\section{Conclusions}

The data analysis shows that the pupils were in the regime of competence for grasping the changed view of symmetry linked to the search for invariance. Nevertheless it does not permit to evaluate how deeply the students have elaborated the contents nor how conscious they were of the whole process. For this reason we plan to carry on with the project in relation with the results of the present work.

\footnotetext{
${ }^{1}$ Q1) If you were the "Rose" trying to explain symmetry to the "Little Prince", which of the following sentences would you use? a) There is symmetry when you can see that, if a line divides a figure in two parts, these parts reflect each other like in a mirror. b) Among the many symmetries that exist there are also the movements that transform a figure so that the resulting figure coincides with the original.

Write the reason of your choice.
} 


\section{References}

Bertozzi E., Levrini O., Rodriguez M (2014) "Symmetry as Core-idea for Introducing Secondary School Students to Contemporary Particle Physics" Procedia - Social and Behavioral Sciences Volume 116, pp. 679-685.

Boniolo, G., Budinich, P. and Trobok, M. (2005) "The role of Mathematics in Physical Sciences. Interdisciplinary and Philosophical Aspects", Springer, pp. 5-8.

Buick J. M. (2007) "Investigating the Correlation between Mathematical Pre-knowledge and Learning Gains in Service Physics.” European Journal of Physics, 28, pp. 1073-1080.

Dirac, P. A. M. (1939) “The Relation Between Mathematics and Physics”, in: Proceedings of the Royal Society (Edinburgh) Vol. 59, II pp. 122-129.

Doran Y. J. (2017) "The Role of Mathematics in Physics: Building Knowledge and Describing the Empirical World”, Onomázein, Special Edition Systemic Functional Linguistics and Legitimation Code Theory, pp. 209- 226.

Feynman, R. (1964-1965) "The Character of Physical Law”, Modern Library 1964 series of Messenger Lectures at Cornel. BBC. [re-editions by MIT Press; Modern Library, 1994].

Fuson, K. C., Kalchman, M., \& Bransford, J. D. (2005) Mathematical understanding: An introduction. In M. S. Donovan \& J. D. Bransford (Eds.), "How students learn: History, mathematics, and science in the classroom", pp. 217-256. Washington, DC: National Academies Press.

Galileo, G., 11 Saggiatore (1623) In: Galilei G (1890-1909) Le opere di Galileo Galileo: Edizione nazionale sotto gli auspici di sua maestà il re d'Italia. Favaro A (ed), Barbera, Firenze, Vol. VI.

Lederman L. M. and Hill C. T. (2000) "Teaching symmetry in the introductory physics curriculum" The Physics Teacher 38, 348.

Leikin, R., Berman, A., \& Zaslavsky, O. (2000) "Applications of symmetry to problem solving". International Journal of Mathematical Education in Science and Technology, 31(6), pp.799-809.

Meltzer D. E. (2002) “The Relationship Between Mathematics Preparation and Conceptual Learning Gains in Physics: A Possible 'Hidden Variable' in Diagnostic Pretest Scores?” Phys. Educ. Res. Am, J. Phys. Suppl. available at www.public.iastate.edu/paper/articles/ms/ms.pdf.

Michelsen C. (2015) "Mathematical Modeling is Also Physics Interdisciplinary Teaching Between Mathematics and Physics in Danish Upper Secondary Education", Physics Education, 50 (489).

Pisano R (2011) Physics-Mathematics Relationship. Historical and Epistemological notes. In Barbin E, Kronfellner M and Tzanakis C, (eds.), Proceedings of the ESU 6 European Summer University History And Epistemology In Mathematics, Verlag Holzhausen GmbH-Holzhausen Publishing Ltd., Vienna, pp. 457-472.

Redish F., Kuo F. (2015) "Language of Physics, Language of Math: Disciplinary Culture and Dynamic Epistemology", Science and Education, vol. 24, Issue 5-6, pp. 561-590.

Rosen, J. and P. Copie' (1982) "On Symmetry in Physical Phenomena, Symmetry of an Electric Field and of a Magnetic Field," a translation of Curie ([1894/1908], 1984), in Joe Rosen (1982), Symmetry in Physics: Selected Reprints. Stony Brook, NY: American Association of Physics Teachers, pp. 17-25.

Thyssen P. and Ceulemans A. (2017) "Shattered Symmetry. Group Theory from the Eightfold Way to the Periodic Table", Oxford University Press. pp. 8

Weyl, H. (1928) Gruppentheorie und Quantenmechanik. Leipzig: S. Hirzel. ([1946] 1966), “The Classical Groups: Their Invariants and Representations" Princeton, NJ: Princeton University Press.

Weyl, H. (1952) "Symmetry", Princeton, NJ: Princeton University Press.

Wigner, E. P. (1960) "The Unreasonable Effectiveness of Mathematics in the Natural Sciences" Communications in Pure and Applied Mathematics, vol. 13, No.1, pp. 1-14.

Wigner, E. P. (1967), Symmetries and Reflections, Bloomington, IN: Indiana University Press. 